BOOK REVIEW

\title{
Dicionário da Saúde e da Prevenção de seus Riscos
}

O Professor Luís Rey, além de renomado parasitologista, consagrado pela sua obra PARASITOLOGIA. Parasitos e Doenças Parasitárias do Homem nas Américas e na África, tornou-se um dicionarista médico ao publicar o Dicionário de Termos Técnicos de Medicina e Saúde que é o melhor, para não dizer único, no Brasil e que obteve em sua primeira edição o Prêmio Jabuti de 2000 da Câmara Brasileira do Livro.

Antes mesmo de lançar pela Editora Guanabara Koogan a terceira edição do seu dicionário de termos técnicos, com 950 páginas, o Dr. Rey lança agora em 2006, pela mesma Editora, o Dicionário da Saúde e da Prevenção de seus Riscos, com 253 páginas, uma versão reduzida do anterior que mantém a mesma estrutura, com os verbetes relacionados com os aspectos do título atual.

Além da qualidade da impressão da obra, chamam a atenção do leitor, as excelentes pranchas coloridas, em encarte de 15 páginas, que são um verdadeiro atlas de anatomia, com todas as estruturas do corpo humano em relevo e profundidade, dando a impressão de tridimensionalidade.

Os verbetes do novo dicionário foram muito bem selecionados, de forma que não precisamos recorrer ao maior para os assuntos relativos à saúde e à sua prevenção. Por outro lado, considerando a redução do volume, torna-se mais fácil o seu manuseio.

O que mais diferencia os dicionários - Termos Técnicos de Medicina e Saúde e Saúde e Prevenção dos seus Riscos - dos demais de medicina e saúde e de quaisquer outros da área médica e biomédica, produzidos em qualquer idioma, são a estrutura, a precisão e a abrangência dos verbetes que são completos pois definem rigorosamente os termos, inclusive a sua origem lingüística, a estrutura no caso de substâncias, parasitos e germes, suas interações com o organismo humano, ações metabólicas e possíveis patologias, forma de diagnóstico, tratamento e prevenção e, muito importante, o termo correspondente em inglês.

Estão de parabéns, os leitores, por esta nova aquisição da literatura médica, o Professor Luís Rey, por esta nova e excelente obra, e a Editora Guanabara Koogan, pelo sucesso anunciado do Dicionário da Saúde e da Prevenção de seus Riscos.

José Rodrigues Coura 